\title{
When science rides the MTA
}

\author{
Alan Dove \\ E-mail: alanwdove@earthlink.net \\ J. Clin. Invest. 110:425-427. doi:10.1172/JCI200216546.
}

Shortly after a large-scale clinical trial in 1955 , the first inactivated polio vaccine was being injected into tens of millions of people around the world - possibly the most successful pharmaceutical product launch in history. Asked why he had not obtained a patent on the phenomenally successful vaccine, Jonas Salk reportedly replied, "That would be like patenting the sun."

A few decades later, this view seemed laughably quaint.

Over the past 20 years, the culture of science has undergone what is arguably its most radical change since World War II: instead of being seen as a strictly public good, basic research is now a patentable commodity.

On the positive side, the commercialization of academic science, particularly biomedical research, has provided a significant source of new funding and sped medical advances from the laboratory to the clinic. According to the Association of University Technology Managers, licensing agreements on patents brought $\$ 1.26$ billion into US academic research centers in 2000. Several universities earned more than $\$ 30$ million in royalties that year, and at both the University of California and Columbia University, patent royalties exceeded \$100 million. Meanwhile, the biotechnology industry, which relies heavily on patented basic science, spent \$10.7 billion on research and development in 2000 - slightly over half the NIH budget for the same year.

The money is nice, but of course it has strings attached. As university budgets have come to rely on the massive revenue streams gushing from faculty patents, pressure is increasing for administrators to turn laboratory findings into cash cows. Meanwhile, scientists must often consult attorneys before sharing reagents with colleagues, lest they jeopardize future royalties. Even gaining access to the data set that undergirds a published paper can create legal headaches.

How did we get to this point?

Eric Campbell, instructor of health policy at Harvard Medical School (Cambridge, Massachusetts, USA) points to a convergence of scientific and business developments in the late 1970s: "It's technology, it's the development of new fields, it's the intellectual property in ... electronics and biotechnology, all of these things happening together."

Then, in 1980, the US Congress took note of a widening gap that seemed to prevent rapidly advancing basic

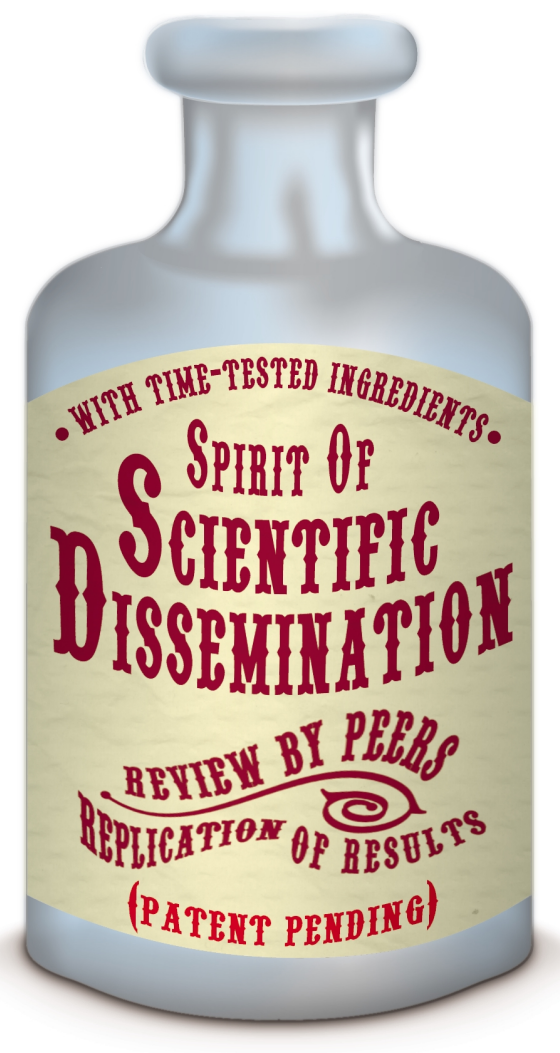

by Ken Beauchamp J. Clin. Invest. research from generating useful products, particularly in medicine. Rather than directly producing products, as it had in Salk's day, government-funded research was more often yielding results that were several steps removed from applicability. But companies were reluctant to pursue these promising leads, which were part of the public domain and therefore not patentable. The result was the BayhDole act of 1980. Among other things, Bayh-Dole requires institutions to seek patents whenever governmentfunded research generates potential products.

The convergence of the Bayh-Dole Act with the meteoric rise of the biotechnology and computer industries was "like the science and technology version of the Perfect Storm," says Campbell, referring to an infamous 1991 collision of synergistic weather systems in the North Atlantic.

While not as deadly as a hurricane, the impact of the Bayh-Dole Act was nonetheless dramatic. In 1979 , universities applied for about 250 patents annually. By the mid-1980s, that number had climbed to about 2,000, and in 1999 the Association of University Technology Managers said that its members had 18,617 active patent licensing agreements. Universities receiving government research grants rapidly sprouted offices of technology licensing (OTLs), and administrators and trustees learned that research royalties could add up to handsome sums.

Corey Goodman, a Howard Hughes Medical Institute (HHMI) investigator at the University of California

(Berkeley, California, USA) who is now president and CEO of Renovis (South San Francisco, California, USA), has seen the results of this transition from both the industry and academic sides. "The 
whole motivation [of the Bayh-Dole Act] is not so much revenue generation for universities, but to get discoveries moved toward applications," says Goodman.

Unfortunately, university administrators sometimes miss this distinction.

Goodman stresses that Berkeley's OTL was quite reasonable, but "when I look around the country, what worries me is that universities have gone a little overboard. People with every reagent that goes out of their lab shouldn't suddenly be asking for ... your firstborn child and maybe even your second or third-born child."

Like many researchers, Goodman

\section{The academy's bottom line. In} 1993, Columbia University's incoming president, George Rupp, touched off a minor firestorm by publicly discussing his plans to expand science departments that were "revenue sources," while cutting back the loss leaders in some humanities fields. Though Rupp's comments were unusually blunt, most university administrators in the US were reaching similar conclusions. Since then, academic institutions have increasingly adopted the organization and rhetoric of corporations, and a focus on research funding and patent royalties has inexorably changed academic culture.

Many universities have now "come to view their stuff through an inappropriate lens of the for-profit activity of the OTL," says Infinity Pharmaceuticals' Steven Holtzman. "We've seen instances where the academy may have a resource ... and yet it's withheld because it's not viewed as profitable enough by the academy. Something's gone wrong there. I think there's been a distortion of the mission of the university."

This unintended consequence of the Bayh-Dole Act seems to operate primarily at the level of university administrators. Other factors have driven change within the scientific community. "Science today is very, very different from science 30 years ago," says Harvard's Eric Campbell. "Science today is big science," often driven by intense competition between large collaborative efforts. According to Campbell's research, it is this competitive atmosphere, rather than pressure to generate profits, which has driven many researchers to withhold reagents from colleagues. has been frustrated by the proliferation of material transfer agreements (MTAs), legal documents designed to protect an inventor's intellectual property rights to a reagent. In extreme cases, an MTA may grant the original inventor ownership of any subsequent discovery made with that reagent, no matter how indirect.

In some cases, such as the Cre-Lox technology developed at DuPont (Wilmington, Delaware, USA), this arises because of the divergent interests of industry and academic science. Using a recombinase system from a bacteriophage, Cre-Lox allows inducible gene deletion in mice, a powerful technique that academic researchers were anxious to use. In an effort to protect its rights to the technology, though, DuPont attached an MTA to the technology that granted the company far-reaching ownership of downstream developments. Academic researchers considered the MTA too intrusive to sign, and the technique remained inaccessible.

But industry hardly has a monopoly on making reagents - and even data difficult to obtain. In a survey of geneticists, Campbell found that $47 \%$ had been denied data or reagents associated with published research at least once in the past three years, and $12 \%$ admitted denying another academician's request for data in the same time period (JAMA, 2002, 287:473-480). The time and effort required to distribute biological materials were most often cited as the reason for denying access, and the second most common reason was a desire to protect a junior colleague's ability to publish subsequent work before turning reagents over to competitors.

So what industry does for money, academics do for papers. And also, perhaps, for money (see "The academy's bottom line").

Whatever the motivation, the impact on science can be disturbing: $28 \%$ of Campbell's survey respondents said they were unable to replicate published research because they were denied access to essential reagents or data. "The integrity of our system of science rests on two pillars ... peer review and replication. If we couldn't [replicate results], would we still believe in cold fusion?" asks Campbell.

With the nudge from the editors of major journals (see "Editors led an

\section{Editors led an unarmed charge.} The crusade for greater access to data and reagents was led primarily by the editors of peer-reviewed journals, some of whom adopted data release policies more than a decade ago. Though each journal has been free to set its own policy, an informal survey conducted for this article suggests considerable convergence.

Science magazine, for example, stipulates that "any reasonable request for materials and methods necessary to verify the conclusions of the experiments reported must be honored," and large data sets must be deposited in a publicly accessible database. Nature requires authors "to make materials and methods used freely available to academic researchers for their own use," with a similar stipulation regarding data access. At least a dozen other leading journals make substantially similar statements in their instructions to authors.

While agreeing that such policies have been important in shaping the debate about reagent access, most observers argue that journals are in a poor position to enforce rules. "In each tier, those journals compete with each other for the best work. There's too much of a conflict there to ask them to really enforce [data sharing rules]," says Renovis's Corey Goodman, adding that "the people who give you the money ought to be setting the rules."

As the people with the money finally begin to take action (see main text), the rules already made by journals provide a surprisingly uniform set of community standards as a starting point.

unarmed charge") and a major genome sequencing controversy, efforts to address these problems are now getting under way.

In 1997, the National Human Genome Research Institute adopted the "Bermuda Rules," which stipulated that government-funded sequencers had to release sequence data publicly within 24 hours of its generation. Celera, the commercial genome sequencing effort, decided to create its own standards for what constituted public release, making its raw sequence data available only through Celera's database rather than the independently operated GenBank database. Celera also required researchers to sign an MTA or buy a subscription 
Choosing an MTA to CYA. One apparently straightforward solution to the problem of intrusive material transfer agreements is to create "universal" MTAs designed to cover ordinary reagent transfers. Is it really necessary to sign a legal agreement before lending a colleague a plasmid, though?

In a word, yes. Besides concerns about intellectual property ownership, heightened fears of lawsuits and recent developments in world events have led attorneys to propose some harrowing scenarios. What if a technician in another laboratory, using one of your reagents, suffers a life-threatening allergic reaction? What if your reagent is used as part of a biological weapon? If you lend something to a corporate laboratory, and it does not work as expected, can you be sued for the company's resulting losses?
Experts also argue that there is no way to know which of a lab's products will have commercial potential and which will not, so some clause protecting intellectual property is essential, even for seemingly trivial transfers. "I call it playing the IP craps table ... sometimes it really pays off. The problem is knowing what's going to be the next Gatorade," says Harvard's Eric Campbell, referring to the University of Florida's phenomenally successful sports rehydration drink.

To address these concerns, the NIH has created a universal biological MTA (UBMTA), which it expects all of its funded researchers to use when transferring reagents. HHMI has taken the concept a step further, with a "short form" MTA for transfers between academic laboratories, and a "long form," with more detailed stipulations about intellectual property ownership, for transfers between academic and corporate laboratories. to the company's database to obtain certain types of data.

When Science published Celera's genome sequencing paper in February 2001, many biologists argued that the company should have been required to deposit all of its data in GenBank. The company and the journal responded that this would have unnecessarily penalized the corporate sequencing effort, which was relying on future income from its proprietary database to bankroll its research.

Spurred partly by the Celera controversy, the National Academy of Sciences convened a workshop on data and reagent sharing in February 2002 and is expected to issue a report with its recommendations on the issue soon. While the NAS is not a major funding source, its recommendations are likely to be heeded by science policy-makers.

In the meantime, both government and industry efforts have already begun to tackle some of the thornier problems of data and reagent access.

Negotiations between the NIH and DuPont have produced agreements to give basic researchers easy access to Cre-Lox technology and another DuPont product, the OncoMouse. "Not only did they grant us a license, but they agreed to grant a license under essentially the same terms to other academic nonprofit institutions engaged in basic research," says Mark Rohrbaugh, acting director of the NIH Office of Technology Transfer. The $\mathrm{NIH}$ is also negotiating agreements to allow federally funded researchers to use commercially developed human embryonic stem cells approved by the Bush administration in August. "To date, the parties have agreed to provide cells without receiving rights to commercial uses of new materials made using the cells," says Rohrbaugh.

In other words, you'll get to keep your firstborn.

The NIH also developed a policy, released at the end of 1999, advocating the use of a universal biological material transfer agreement (UBMTA) when reagents are transferred between academic researchers (see "Choosing an MTA to CYA"). To date, over 100 institutions around the world have agreed to use the agreement as a model, which promises to simplify reagent sharing. Grant applicants can also now include in their grants the costs of distributing reagents, a step that should help overcome the logistical hurdles of sharing complex bio- logical materials.

The HHMI has followed a similar strategy. "HHMI has adopted several form MTAs, including a 'short form' agreement ... that is even less burdensome than the [NIH] UBMTA," says Joan Leonard, vice president and general counsel at HHMI. The HHMI policies on material transfers are online at http://www.hhmi.org/ ogc/guide.html.

More recently, the NIH has been addressing the problem of data sharing and is currently collecting comments on the draft guidelines published on the agency's website (http://www.nih.gov).

Ultimately, some of the new measures may help address the shift in academic culture as well. By having standardized MTAs, for example, funding agencies are implicitly defining community standards for reagent sharing. If institutions want to apply different standards, says Steven Holtzman, president and CEO of Infinity Pharmaceuticals Inc. and a member of an NAS advisory panel studying reagent and data access, they should ask, "Why is your action departing from this effecting more effectively the mission of the university?' The answer 'I can make more money off it,' ain't an answer." 